\title{
Microalgal biomass as a fermentation feedstock for bioethanol production
}

\begin{abstract}
Background: The increasing cost of fossil fuels as well as the escalating social and industrial awareness of the environmental impacts associated with the use of fossil fuels has created the need for more sustainable fuel options. Bioethanol, produced from renewable biomass such as sugar and starch materials, is believed to be one of these options, and it is currently being harnessed extensively. However, the utilization of sugar and starch materials as feedstocks for bioethanol production creates a major competition with the food market in terms of land for cultivation, and this makes bioethanol from these sources economically less attractive. Result: This study explores the suitability of microalgae (Chlorococum sp.) as a substrate for bioethanol production via yeast (Saccharomycesbayanus)under different fermentation conditions. Results show a maximum ethanol concentration of $3.83 \mathrm{~g} \mathrm{~L}-1$ obtained from $10 \mathrm{~g}$ L-1 of lipid-extracted microalgae debris. Conclusion: This productivity level $(\sim 38 \% \mathrm{w} / \mathrm{w})$, which is in keeping with that of current production systems endorses microalgae as a promising substrate for bioethanol production.
\end{abstract}

Keyword: Microalgae; Fermentation feedstocks; Yeast fermentation; Bioethanol 